\title{
Genomics of Preterm Birth-Evidence of Association and Evolving Investigations
}

\author{
Jessica A. McPherson, MD $^{1}$ Tracy A. Manuck, MD ${ }^{1,2}$ \\ 1 Division of Maternal-Fetal Medicine, Department of Obstetrics and \\ Gynecology, University of North Carolina School of Medicine, \\ Chapel Hill, North Carolina \\ 2 Department of Obstetrics and Gynecology, University of Utah, \\ Salt Lake City, Utah
}

\begin{abstract}
Address for correspondence Jessica A. McPherson, MD, Department of Obstetrics and Gynecology, University of North Carolina School of Medicine, 3010 Old Clinic Building, Campus Box 7516, Chapel Hill, NC 27599 (e-mail: jessica_mcpherson@med.unc.edu).
\end{abstract}

Am J Perinatol 2016;33:222-228.

\begin{abstract}
Keywords

- preterm birth

- genetics

- phenotype

- fetal genotype

- maternal genotype

- heritability

Preterm birth (PTB) is a large public health problem in the United States and worldwide. There is a clear genetic component to the pathogenesis of PTB, as evidenced by twin studies, heritability studies, and investigations from large population databases. Although numerous single nucleotide polymorphisms have been associated with PTB, results have been inconsistent and overall disappointing. With recent advances in genetic technology, investigations are moving beyond simple, more traditional candidate gene studies, and have expanded to encompass more exploratory analyses using high-throughput genetic techniques. Care should be taken to consider the potential impact of fetal genotype, the environment, and gene-drug interactions (pharmacogenomics) in addition to maternal genotype. Future research should capitalize on evolving analytic techniques, including pathway analyses and correlation of genetic and functional data to optimize discovery, increase knowledge regarding prematurity pathogenesis, and begin to develop novel therapeutic strategies.
\end{abstract}

\section{Problem of Prematurity}

Each year, worldwide, approximately 15 million infants are born preterm less than 37 weeks' gestation, including 446,850 preterm infants in the United States alone. ${ }^{1-3}$ Preterm birth (PTB) is the second leading cause of death worldwide among children under the age of 5 , and is the leading cause of newborn death in the United States. ${ }^{1,2}$ Surviving neonates have significant risk of both major and minor medical problems (with the potential to affect all major organ systems as well as cognitive development). These morbidities emerge in the immediate newborn period and may persist into childhood and adulthood. ${ }^{4-7}$ The combination of prolonged hospitalization after birth, increased need for early intervention services, and care for related medical conditions result in staggering healthcare costs related to prematurity. ${ }^{8-12}$

Spontaneous PTB is multifactorial and thought to be a "final common pathway," as it is associated with a variety of

received

November 18, 2015

accepted after revision

November 24, 2015

published online

January 22, 2016 medical and obstetrical conditions. It is traditionally classified as either spontaneous (e.g., attributed to preterm premature rupture of membranes [PPROM] or idiopathic preterm contractions) or indicated (e.g., attributed to medical eclampsia or fetal growth restriction). Increasing evidence suggests that there may be substantial phenotypic overlap between spontaneous and indicated PTB, as women with a history of a prior spontaneous PTB have an elevated risk for indicated PTB in a subsequent pregnancy and vice versa. ${ }^{13}$ It is possible that PTB, regardless of eventual phenotype, all start from a single common aberration, and then different environmental and genetic influences lead to divergent clinical phenotypes, but this is a largely untested hypothesis. However, some researchers have recently found evidence of placental insufficiency even in cases of idiopathic PTB, lending credence to this theory of a single underlying etiology for all premature deliveries. Proponents of this hypothesis

Copyright $\odot 2016$ by Thieme Medical Publishers, Inc., 333 Seventh Avenue, New York, NY 10001, USA. Tel: +1(212) 584-4662.
DOI http://dx.doi.org/ 10.1055/s-0035-1571144. ISSN 0735-1631. and/or fetal causes necessitating delivery, such as pre- 
suggest that whether the PTB phenotypically is spontaneous or indicated is determined very early in pregnancy perhaps even before or around the time of implantation and placentation. ${ }^{14,15}$

Thus, although many factors that lead to PTB have been described, overall, instigating causes are poorly understood because the majority of risk factors are neither sufficient nor necessary to result in PTB. Because PTB is multifactorial, both exogenous and endogenous risk factors (and the interaction of these risk factors) contribute to the underlying pathophysiology. Maternal and fetal genotypes are two risk factors that have both been consistently implicated in the pathogenesis of PTB across multiple studies, populations, and prematurity phenotypes. Unfortunately, results of individual genetic studies have been inconsistent and difficult to replicate. This review focuses on an exploration of the evidence of the heritability of PTB and the various approaches that individual researchers have taken to investigate the genetic contributions to PTB with a discussion of representative associated results. Finally, we discuss opportunities for future research direction.

\section{Evidence of Preterm Birth Heritability}

Multiple studies suggest genetic predisposition to PTB. One of the strongest, most consistent risk factors for PTB is a personal history of PTB. The odds of recurrent PTB (spontaneous or indicated) vary but range from 1.6 to 10.6 ; higher odds are seen for women with multiple prior PTB and a history of very early prior PTB. ${ }^{13,16,17}$ In one study of consecutive pregnancies, among women with a recurrent PTB, 49\% delivered within 1 week of the gestational age of their first delivery, and $70 \%$ had a recurrent PTB within 2 weeks of the gestational age of their first delivery, suggesting that delivery gestational age may be "genetically programmed" for some women. ${ }^{16}$ Other studies of consecutive pregnancies have also confirmed that the greatest risk of recurrent PTB tends to occur around the same gestational age that the РТВ occurred in the first pregnancy. This observation is true regardless of the prematurity subtype (indicated PTB vs. spontaneous PTB). ${ }^{13}$

The rate of PTB varies by race and ethnicity and is highest among women of African descent. ${ }^{18-20}$ This ethnic disparity persists after controlling for social and demographic confounders. $^{21}$ In a study of mixed race couples, there was a graduated risk of PTB $<35$ weeks' gestation; compared with a referent group of white mothers-white fathers, the risk increased steadily with increasing contribution of black genes, from a slightly increased risk among white mothersblack fathers (adjusted odds ratio [aOR], 1.28; 95\% confidence interval [CI], 1.13-1.46) to a moderately increased risk among black mothers-white fathers (aOR, 2.10; 95\% CI, 1.68-2.62) to the highest risk among black mothers-black fathers (aOR, 2.28; 95\% CI, 2.18-2.39).22 Similar results were found in a different cohort, where the racial contribution of father was again noted to be important, and again, black fathers did not increase the risk of PTB as much as black mothers did among interracial couples. ${ }^{23}$ These data provided further credence to the notion that risk-predisposing alleles may be more prevalent in the black population, but also emphasized the importance of the contribution of both maternal and paternal genes. In addition, blacks have been found to have higher risks of recurrent $\mathrm{PTB}$, and their recurrences tend to occur at earlier gestational ages (mean of 31 vs. 33 weeks' gestation) compared with whites. Another study examining clinical phenotypes of PTB found blacks were more likely to have maternal stress and cervical insufficiency phenotypes, whereas white women had higher rates of decidual hemorrhage and placental dysfunction. ${ }^{24}$ Other studies have found significant differences in biomarker profiles between blacks and whites; with generally higher proinflammatory changes in blacks. ${ }^{25-27}$ Taken together, this body of literature suggests fundamental pathologic differences in PTB between blacks and whites, of which there is likely a genetic component. ${ }^{28}$

Family studies have also suggested a genetic predisposition to PTB. In 1998, Winkvist et al studied a large Swedish medical birth registry, and found an increased risk for PTB among women whose sisters had a prior PTB (aOR, 1.94; 95\% CI, 1.26-2.99). ${ }^{29}$ Twin studies provide another means to estimate heritability of a condition. Indeed, using data from large cohorts of monozygotic and dizygotic twin pairs, investigators have estimated that the concordance of birth outcomes among twin sibling pairs for the first-born offspring is 19 to $34 \%$, a rate that is greater than expected by chance or environment alone. ${ }^{30-32}$

Intergenerational studies across multiple different populations have provided further evidence for a genetic predisposition to PTB. In 1997, Porter et al used the Utah Population Database to study birth outcomes across generations. Women who themselves were born preterm were matched on several characteristics to women born at term, and the delivery gestational ages of their offspring were compared. Preterm mothers had significantly higher risks for PTB than term mothers (OR, 1.18; 95\% CI, 1.02-1.37), and there was an inverse relationship with the maternal gestational age at birth (those mothers who themselves were delivered $<30$ weeks had higher odds for PTB; OR, 2.38; 95\% CI, 1.37-4.16). ${ }^{33}$ Similar results were found in a Swedish cohort, which confirmed that being preterm was associated with an increased risk of then delivering a preterm child later in life (aOR, 1.39; 95\% CI, 1.29-1.50). ${ }^{34}$ Another large population study from Utah separated the effects of the fetal and maternal genomes on gestational age, and estimated that the heritability of gestational age ranges from 13.3 to $24.5 \%{ }^{35}$

\section{Identification of "Prematurity Gene(s)"- The Candidate Gene Approach}

Candidate gene studies focus on specific, biologically relevant regions of the genome that are suspected to be involved in the pathogenesis of a condition. They are generally the most affordable type of genetic study (although the cost per polymorphism can be relatively expensive depending on the technology used). Candidate gene studies can include one gene or a handful of genes or encompass a larger gene panel (either custom or predefined by a manufacturer). ${ }^{36}$ This approach is limited by reliance on a priori knowledge about known or theoretical biology of disease. Because allele 
frequencies vary by race/ethnicity, critics also argue that population stratification contributes to inconsistent results between populations. ${ }^{37}$ Although population stratification is a concern in all genetic studies, in the case of candidate gene studies, it is particularly highlighted due to the smaller number of genetic variants that are often examined.

The majority of published studies of the genetics of PTB have been candidate gene studies. Many of these have focused on polymorphisms in genes involved with inflammation or the response to infection. Previous work has provided evidence that inflammation is involved in preterm labor and delivery as evidenced through increased levels of inflammatory markers in women with spontaneous PTB. ${ }^{38,39}$ Although inflammation is often present in the decidual tissues of women delivering preterm, the association is not simple or straightforward. ${ }^{40}$ An increase in inflammatory cytokines is not seen in all PTB, and many women with PTB have chronic inflammation (e.g., due to obesity or autoimmune disease) but no evidence of infection. ${ }^{41-43}$ Likewise, some have infection but no inflammation. ${ }^{43}$ Thus, other factors (perhaps genetics or other environmental influences or exposures) impact an individual's response to noxious infectious or proinflammatory stimuli. Multiple studies have documented associations between cytokine polymorphisms and PTB, most consistently interleukin (IL)-1, IL-4, matrix metalloproteinases, natural killer cells, and toll-like receptors. ${ }^{44-47}$ Because polymorphisms in these genes are not associated with PTB in all women from all populations, this suggests a role for gene-environment interactions, but the mechanisms remain poorly understood. ${ }^{48}$

Recently, several groups of investigators have performed systematic reviews and/or meta-analyses of genetic association studies, providing increased power and evidence beyond what the individual studies have been able to provide. The incorporation of gene-environment interaction information into candidate gene studies (either at the onset or post hoc) is important and can add a key additional element contributing depth to the analysis.

One example is the genetic review published by Crider et al in 2005. In this review of 18 studies, the authors summarized the associations between genetic polymorphisms in inflammatory cytokines and other immune modulators and PTB. ${ }^{45}$ The authors noted that the majority of sample sizes were small, frequently were convenience samples of high-risk referral hospital populations, and study outcomes and definitions varied widely. The most frequently studied and most consistent positive association was seen with the tumor necrosis factor $\alpha$ (TNF- $\alpha$ ) gene. ${ }^{45}$ TNF- $\alpha$ is a proinflammatory cytokine which influences cervical remodeling and fetal membrane integrity; carriage of the minor allele at position $-308 \mathrm{~A}$ is associated with an increased risk of PTB and chorioamnionitis. ${ }^{49}$ In one functional study, women with the minor allele at $-308 \mathrm{~A}$ produce significantly higher levels of TNF- $\alpha$ in response to lipopolysaccharide stimuli compared with women with the major allele, which may be a possible explanation for this association. ${ }^{50}$ Macones et al found a possible gene-environment interaction involving TNF- $\alpha$; carriage of the $-308 \mathrm{~A}$ allele alone was associated with an increased risk of PTB (OR, 2.7; 95\% CI, 1.7-2.5), but among women who also had bacterial vaginosis, the risk was even higher (OR, 6.1; 95\% CI, 1.9-21.0). ${ }^{51}$

Another example of a modern application of candidate gene data in the study of PTB is exemplified by a metaanalysis published in 2013 by $\mathrm{Wu}$ et al. These authors performed a systematic review and meta-analysis evaluating the association between IL- 6 and PTB. This association had previously been inconsistently reported. ${ }^{52}$ Ten studies evaluating the maternal and/or fetal genotype for rs1800795 (a single nucleotide polymorphism [SNP] in the IL-6 promoter region, also commonly referred to as the "IL-6 -174" polymorphism) were analyzed, and encompassed 1,165 PTB and 3,830 term controls. Among women of European ancestry, the rs1800795 CC genotype was protective against PTB (OR, 0.68; 95\% CI, 0.51-0.91), but there was no association between the rs1800795 genotype and PTB among nonEuropean women (OR, 1.01; 95\% CI, 0.59-1.75). When fetal genotypes were analyzed, no significant association between rs1800795 genotype and PTB (OR, 0.98; 95\% CI, 0.72-1.33) was found. These findings emphasize the important role of population stratification in genetic association studies. ${ }^{52}$

Candidate gene studies have also examined SNPs in other proposed PTB etiologic pathways. For example, investigators have studied genes that may be associated with uterine quiescence, including SNPs in the A kinase anchor protein (PRKA) gene, known to impact muscle contraction and myometrial quiescence, and found an association between two polymorphisms (rs119672 and rs169412) and term delivery. ${ }^{53}$ Other studies have also investigated polymorphisms in the human relaxin gene $(R L N)$; SNPS in this gene have been associated with PPROM, and others have theorized that it may also impact uterine quiescence. ${ }^{54}$ In a small nested case-control study performed by the Danish National Birth Registry, maternal RLN2 genotype was associated with PTB and PPROM. ${ }^{55}$

Numerous other genes have been associated with PTB through candidate-gene investigations; the aforementioned genes are merely examples. A complete listing of all genes would not be possible and is outside of the scope of this article. A comprehensive list (as of 2012), including 617 genes identified by curation of more than 900 articles, microarray and proteomic databases, and pathways, is available online through the Database for Preterm Birth (dbPTB) project, hosted by Brown University (database URL: http://ptbdb.cs. brown.edu/dbPTBv1.php) (- Table 1). ${ }^{56}$

\section{Larger Scale Genome-Wide Investigations, Linkage Analyses, and Pathway Analyses}

High-throughput genotyping approaches include larger SNP panels, genome wide association studies (GWAS, covering millions of SNPs), microarray, and whole exome and whole genome sequencing. The advantage of these approaches is that there is no (or significantly less) bias in the selection of genes. This allows for increased "discovery" science and exploration of previously unsuspected avenues of genetic association, and exploits the power of gene ontology by grouping genes with similar basic 
Table 1 Examples of publically available analytic tools for genetic research of prematurity

\begin{tabular}{|c|c|c|}
\hline Broad category & Name & Brief description \\
\hline $\begin{array}{l}\text { Database of genes } \\
\text { associated with PTB }\end{array}$ & Database for Preterm Birth (dbPTB) ${ }^{64}$ & $\begin{array}{l}\text { Web-based aggregation tool to organize genes, genetic } \\
\text { variations, and pathways involved in PTB; curated list of } \\
\text { genes }\end{array}$ \\
\hline \multirow[t]{2}{*}{$\begin{array}{l}\text { Genome association } \\
\text { analysis tool set }\end{array}$} & PLINK $^{65}$ & $\begin{array}{l}\text { Analysis of genotype and phenotype data; designed to } \\
\text { perform a range of basic, large scale analyses in a } \\
\text { computationally efficient manner }\end{array}$ \\
\hline & $\begin{array}{l}\text { Variant Annotation, Analysis, and } \\
\text { Search Tool (VAAST) } 66,67\end{array}$ & $\begin{array}{l}\text { Probabilistic search tool for identifying damaged genes } \\
\text { and their disease causing variants in personal genome } \\
\text { sequences }\end{array}$ \\
\hline \multirow[t]{4}{*}{ Pathway analysis } & $\begin{array}{l}\text { Database for Annotation, } \\
\text { Visualization, and Integrated } \\
\text { Discovery (DAVID) v. } 6.7^{68,69}\end{array}$ & $\begin{array}{l}\text { Comprehensive set of functional annotation tools for } \\
\text { investigators to understand biological meaning behind } \\
\text { large lists of genes }\end{array}$ \\
\hline & $\begin{array}{l}\text { Kyoto Encyclopedia of Genes and } \\
\text { Genomes (KEGG) }\end{array}$ & $\begin{array}{l}\text { Database resource for understanding high-level } \\
\text { functions and utilities of the biologic system }\end{array}$ \\
\hline & $\begin{array}{l}\text { Protein ANalysis THrough } \\
\text { Evolutionary } \\
\text { Relationships (PANTHER) }\end{array}$ & $\begin{array}{l}\text { Classifies proteins and their genes to facilitate } \\
\text { high-throughput analysis }\end{array}$ \\
\hline & $\begin{array}{l}\text { Phenotype driven variant ontological } \\
\text { re-ranking tool (Phevor) }\end{array}$ & $\begin{array}{l}\text { Integrates phenotype, gene function, and disease } \\
\text { information with personal genomic data for improved } \\
\text { power to identify disease-causing alleles. Combines } \\
\text { knowledge from biomedical ontologies with outputs of } \\
\text { variant prioritization tools }\end{array}$ \\
\hline Evolutionary biology & GEneSTATION $1.0^{71}$ & $\begin{array}{l}\text { Resource of diverse evolutionary and functional genomic } \\
\text { data for studying the evolution of pregnancy-associated } \\
\text { tissues and phenotypes }\end{array}$ \\
\hline
\end{tabular}

Abbreviation: PTB, preterm birth.

functions. This methodology is not without drawbacks, however. Most high-throughput genotyping platforms are expensive, and resultant data analyses are challenging due to concerns regarding multiple comparisons and high thresholds for statistical significance to reduce the probability of false positives. Further, there is no clear "roadmap" regarding the most appropriate methodology for this type of genetic analysis, and the analytic methods are complex due to the massive volume of data, and are thus continuously evolving. However, an increasing number of tools have been designed, and enable scientists to sort through and analyze these complex genetic data. Many are available online, at no charge ( - Table 1 ). These include pathway analysis tools, which provide the means to take a large gene list and pare it down to a smaller, more meaningful and focused prioritized list. Described below are examples of high-throughput genetic analyses of PTB, demonstrating how these types of analyses provide additional power in the study of prematurity.

Velez et al evaluated 1,536 SNPs in 130 candidate genes from hypothesized PTB pathways, and found an association between maternal genotype and prematurity among several complement-coagulation pathway genes among Caucasians (including factor V, factor VII, tissue plasminogen activator). ${ }^{57}$ The authors also found an association between fetal genotype and inflammatory pathways (IL-10 receptor antagonist), leading them to conclude that there are potentially different maternal and fetal genetic risks for PTB among Caucasians. ${ }^{57}$ This is in contrast to the results of companion studies performed by the same group among a cohort of African Americans, which demonstrated a strong association between genes involved in infection and inflammation (namely, IL-10 and fetal IL-2 receptor $\beta$ ), and PTB. In the African American analysis, there were more pronounced fetal than maternal effects. ${ }^{58}$

Zhang et al reported results from a large, multicenter GWAS study of early PTB, which included 959 case mothers and 979 case neonates (all delivered $<34$ weeks' gestation) compared with 960 control mothers and 985 control neonates (all delivered $\geq 39$ weeks' gestation). ${ }^{59}$ Both maternal and fetal samples were genotyped with a large established SNP Array (Affymetrix 6.0; Affymetrix, Santa Clara, CA). Although 20 maternal SNPs had $p$-values ranging from $1.0 \times 10^{-6}$ to $4.10^{-5}$, no maternal SNPs reached formal genome-wide significance. Two neonatal SNPs, rs17527054 (located on chromosome 6p22 in the area of the major histocompatibility complex) and rs3777722 (located on chromosome 6q27 in the RNASET2 gene) reached genome-wide significance, but the findings were unable to be replicated after adjusting for multiple comparisons in a validation cohort. The authors noted that many of their top SNPs, although not reaching formal genome wide significance, were located in genes or genomic regions involved in pathways previously implicated in PTB (e.g., inflammation and immunity). ${ }^{59}$

In another review which included a pathway analysis, Capece et al identified 15 genetic association studies conducted in 3,600 women encompassing 2,175 SNPs in 274 genes. The authors used Ingenuity Pathway Analysis (IPA; QIAGEN Redwood City, www.qiagen.com/ingenuity) to determine if genetic associations differed between idiopathic PTB and PPROM. They concluded 
that idiopathic spontaneous PTB is associated with autoimmune and hormonal regulation pathways; in contrast, hematologic/ coagulation function disorders, collagen metabolism, matrix degradation, and local inflammation pathways were implicated in PPROM. ${ }^{60}$

\section{Identification of "Prematurity Gene(s)"-The Future}

There is a clear need to optimize genetic studies of prematurity. Utilization of large, multiplex genetic platforms focused on individuals with a specific PTB phenotype or individuals from a single family or families with PTB may increase the likelihood of detecting genetic variants associated with this disease. Furthermore, as genetic analysis technology continues to improve, utilization of next-generation sequencing data are increasingly more accessible and widespread, and will help researchers move away from preconceived notions regarding the genetic variants involved in the pathogenesis of prematurity.

Although this review focuses on genomics, the importance of epigenetics and proteomics in the study of PTB should not be overlooked, as these areas also provide very valuable information into the pathophysiology of this complex disorder. $^{61,62}$ It is an exciting time to utilize the increasing knowledge of biologic pathways, harness the power of analytic algorithms, as well as consider gene-environment and gene-drug (pharmacogenomics) effects when designing studies, analyzing data, and synthesizing results. ${ }^{63}$

\section{Conclusion}

PTB is a large public health problem in the United States and worldwide. Although there is a clear genetic component to the pathogenesis of PTB, maternal and fetal genotypes are neither necessary nor sufficient for the development of this complex syndrome. Care should be taken to consider not only maternal genetic effects but also the potential impact of fetal genotype, the environment, and gene-drug interactions (pharmacogenomics). Future research should capitalize on evolving analytic techniques, including pathway analyses and correlation of genetic and functional data to optimize discovery, increase knowledge regarding prematurity pathogenesis, and begin to develop novel therapeutic strategies.

\section{Disclosures}

Dr. Manuck serves on the scientific advisory board of Sera Prognostics, a private company that was established to create a commercial test to predict preterm birth and other obstetric complications. Dr. McPherson does not have any potential conflict of interest to report.

\section{Financial Support}

This work was supported by the Eunice Kennedy Shriver National Institute of Child Health and Human Development 5K23HD067224 (Dr. Manuck).

\section{References}

1 Blencowe H, Cousens S, Chou D, et al; Born Too Soon Preterm Birth Action Group. Born too soon: the global epidemiology of 15 million preterm births. Reprod Health 2013;10(Suppl 1):S2

2 Blencowe H, Cousens S, Oestergaard MZ, et al. National, regional, and worldwide estimates of preterm birth rates in the year 2010 with time trends since 1990 for selected countries: a systematic analysis and implications. Lancet 2012;379(9832):2162-2172

3 Martin JA, Hamilton BE, Osterman MJ. Births in the United States, 2014. NCHS Data Brief 2015;(216):1-8

4 Serenius $F$, Källén $K$, Blennow $M$, et al; EXPRESS Group. Neurodevelopmental outcome in extremely preterm infants at 2.5 years after active perinatal care in Sweden.JAMA 2013;309(17):1810-1820

5 Moore T, Hennessy EM, Myles J, et al. Neurological and developmental outcome in extremely preterm children born in England in 1995 and 2006: the EPICure studies. BMJ 2012;345:e7961

6 Pyhälä R, Hovi P, Lahti M, et al. Very low birth weight, infant growth, and autism-spectrum traits in adulthood. Pediatrics 2014; 134(6):1075-1083

7 Sammallahti S, Pyhälä R, Lahti M, et al. Infant growth after preterm birth and neurocognitive abilities in young adulthood. J Pediatr 2014;165(6):1109-1115.e3

8 Schmitt SK, Sneed L, Phibbs CS. Costs of newborn care in California: a population-based study. Pediatrics 2006;117(1):154-160

9 Phibbs CS, Schmitt SK. Estimates of the cost and length of stay changes that can be attributed to one-week increases in gestational age for premature infants. Early Hum Dev 2006;82(2):85-95

10 Johnson TJ, Patel AL, Jegier BJ, Engstrom JL, Meier PP. Cost of morbidities in very low birth weight infants. J Pediatr 2013; 162(2):243-49.e1

11 Gilbert WM, Nesbitt TS, Danielsen B. The cost of prematurity: quantification by gestational age and birth weight. Obstet Gynecol 2003;102(3):488-492

12 Clements KM, Barfield WD, Ayadi MF, Wilber N. Preterm birthassociated cost of early intervention services: an analysis by gestational age. Pediatrics 2007;119(4):e866-e874

13 Ananth CV, Getahun D, Peltier MR, Salihu HM, Vintzileos AM. Recurrence of spontaneous versus medically indicated preterm birth. Am J Obstet Gynecol 2006;195(3):643-650

14 Kim CJ, Romero R, Chaemsaithong P, Kim JS. Chronic inflammation of the placenta: definition, classification, pathogenesis, and clinical significance. Am J Obstet Gynecol 2015;213(4, Suppl):S53-S69

15 Morgan TK, Tolosa JE, Mele L, et al; Eunice Kennedy Shriver National Institute of Child Health and Human Development Maternal-Fetal Medicine Units Network. Placental villous hypermaturation is associated with idiopathic preterm birth. J Matern Fetal Neonatal Med 2013;26(7):647-653

16 Bloom SL, Yost NP, McIntire DD, Leveno KJ. Recurrence of preterm birth in singleton and twin pregnancies. Obstet Gynecol 2001; 98(3):379-385

17 Esplin MS, O'Brien E, Fraser A, et al. Estimating recurrence of spontaneous preterm delivery. Obstet Gynecol 2008;112(3):516-523

18 Manuck TA, Lai Y, Meis PJ, et al; Eunice Kennedy Shriver National Institute of Child Health and Human Development (NICHD) Maternal-Fetal Medicine Units Network (MFMU). Admixture mapping to identify spontaneous preterm birth susceptibility loci in African Americans. Obstet Gynecol 2011;117(5): 1078-1084

19 Anum EA, Springel EH, Shriver MD, Strauss JF III. Genetic contributions to disparities in preterm birth. Pediatr Res 2009;65(1):1-9

20 Menon R, Pearce B, Velez DR, et al. Racial disparity in pathophysiologic pathways of preterm birth based on genetic variants. Reprod Biol Endocrinol 2009; 7:62

21 Goldenberg RL, Cliver SP, Mulvihill FX, et al. Medical, psychosocial, and behavioral risk factors do not explain the increased risk for low birth weight among black women. Am J Obstet Gynecol 1996; 175(5):1317-1324 
22 Palomar L, DeFranco EA, Lee KA, Allsworth JE, Muglia LJ. Paternal race is a risk factor for preterm birth. Am J Obstet Gynecol 2007; 197(2):152.e1-152.e7

23 Simhan HN, Krohn MA. Paternal race and preterm birth. Am J Obstet Gynecol 2008;198(6):644.e1-644.e6

24 Manuck TA, Esplin MS, Biggio J, et al; Eunice Kennedy Shriver National Institute of Child Health and Human Development Genomics and Proteomics Network for Preterm Birth Research. The phenotype of spontaneous preterm birth: application of a clinical phenotyping tool. Am J Obstet Gynecol 2015;212(4):487. e1-487.e11

25 Menon R, Thorsen P, Vogel I, et al. Racial disparity in amniotic fluid concentrations of tumor necrosis factor (TNF)-alpha and soluble TNF receptors in spontaneous preterm birth. Am J Obstet Gynecol 2008;198(5):533.e1-533.e10

26 Brou L, Almli LM, Pearce BD, et al. Dysregulated biomarkers induce distinct pathways in preterm birth. BJOG 2012;119(4):458-473

27 Menon R, Williams SM, Fortunato SJ. Amniotic fluid interleukin1beta and interleukin- 8 concentrations: racial disparity in preterm birth. Reprod Sci 2007;14(3):253-259

28 Kistka ZA, Palomar L, Lee KA, et al. Racial disparity in the frequency of recurrence of preterm birth. Am J Obstet Gynecol 2007;196(2): 131.e1-131.e6

29 Winkvist A, Mogren I, Högberg U. Familial patterns in birth characteristics: impact on individual and population risks. Int J Epidemiol 1998;27(2):248-254

30 Clausson B, Lichtenstein P, Cnattingius S. Genetic influence on birthweight and gestational length determined by studies in offspring of twins. BJOG 2000;107(3):375-381

31 Treloar SA, Macones GA, Mitchell LE, Martin NG. Genetic influences on premature parturition in an Australian twin sample. Twin Res 2000;3(2):80-82

32 Kistka ZA, DeFranco EA, Ligthart L, et al. Heritability of parturition timing: an extended twin design analysis. Am J Obstet Gynecol 2008;199(1):43.e1-43.e5

33 Porter TF, Fraser AM, Hunter CY, Ward RH, Varner MW. The risk of preterm birth across generations. Obstet Gynecol 1997;90(1): 63-67

34 Bladh M, Josefsson A, Carstensen J, Finnström O, Sydsjö G. Intergenerational cohort study of preterm and small-for-gestationalage birth in twins and singletons. Twin Res Hum Genet 2015; 18(5):581-590

$35 \mathrm{Wu} \mathrm{W}$, Witherspoon DJ, Fraser A, et al. The heritability of gestational age in a two-million member cohort: implications for spontaneous preterm birth. Hum Genet 2015;134(7):803-808

36 Zhu M, Zhao S. Candidate gene identification approach: progress and challenges. Int J Biol Sci 2007;3(7):420-427

37 Tabor HK, Risch NJ, Myers RM. Candidate-gene approaches for studying complex genetic traits: practical considerations. Nat Rev Genet 2002;3(5):391-397

38 Goldenberg RL, Andrews WW, Mercer BM, et al; National Institute of Child Health and Human Development Maternal-Fetal Medicine Units Network. The preterm prediction study: granulocyte colonystimulating factor and spontaneous preterm birth. Am J Obstet Gynecol 2000;182(3):625-630

39 Ruiz RJ, Jallo N, Murphey C, Marti CN, Godbold E, Pickler RH. Second trimester maternal plasma levels of cytokines IL-1Ra, Il-6 and IL-10 and preterm birth. J Perinatol 2012;32(7):483-490

40 Kramer MS, Kahn SR, Platt RW, et al. Mid-trimester maternal plasma cytokines and CRP as predictors of spontaneous preterm birth. Cytokine 2010;49(1):10-14

41 Cnattingius S, Villamor E, Johansson S, et al. Maternal obesity and risk of preterm delivery. JAMA 2013;309(22):2362-2370

42 Johnson MJ, Petri M, Witter FR, Repke JT. Evaluation of preterm delivery in a systemic lupus erythematosus pregnancy clinic. Obstet Gynecol 1995;86(3):396-399

43 Combs CA, Gravett M, Garite TJ, et al; ProteoGenix/Obstetrix Collaborative Research Network. Amniotic fluid infection, inflam- mation, and colonization in preterm labor with intact membranes. Am J Obstet Gynecol 2014;210(2):125.e1-125.e15

44 Fortunato SJ, Menon R, Velez DR, Thorsen P, Williams SM. Racial disparity in maternal-fetal genetic epistasis in spontaneous preterm birth. Am J Obstet Gynecol 2008;198(6):666.e1-666.e9, discussion 666.e9-666.e10

45 Crider KS, Whitehead N, Buus RM. Genetic variation associated with preterm birth: a HuGE review. Genet Med 2005;7(9): 593-604

46 Schmid M, Haslinger P, Stary S, Leipold H, Egarter C, Grimm C. Interleukin-1 beta gene polymorphisms and preterm birth. Eur J Obstet Gynecol Reprod Biol 2012;165(1):33-36

47 Marconi C, de Andrade Ramos BR, Peraçoli JC, Donders GG, da Silva MG. Amniotic fluid interleukin-1 beta and interleukin-6, but not interleukin-8 correlate with microbial invasion of the amniotic cavity in preterm labor. Am J Reprod Immunol 2011;65(6): 549-556

48 Cappelletti M, Della Bella S, Ferrazzi E, Mavilio D, Divanovic S. Inflammation and preterm birth. J Leukoc Biol 2015

49 Simhan HN, Krohn MA, Zeevi A, Daftary A, Harger G, Caritis SN. Tumor necrosis factor-alpha promoter gene polymorphism -308 and chorioamnionitis. Obstet Gynecol 2003;102(1):162-166

50 Hernandez-Guerrero C, Monzon-Bordonaba F, Jimenez-Zamudio $\mathrm{L}$, et al. In-vitro secretion of proinflammatory cytokines by human amniochorion carrying hyper-responsive gene polymorphisms of tumour necrosis factor-alpha and interleukin-1beta. Mol Hum Reprod 2003;9(10):625-629

51 Macones GA, Parry S, Elkousy M, Clothier B, Ural SH, Strauss JF III. A polymorphism in the promoter region of TNF and bacterial vaginosis: preliminary evidence of gene-environment interaction in the etiology of spontaneous preterm birth. Am J Obstet Gynecol 2004;190(6):1504-1508, discussion 3A

$52 \mathrm{Wu} \mathrm{W}$, Clark EA, Stoddard GJ, et al. Effect of interleukin-6 polymorphism on risk of preterm birth within population strata: a meta-analysis. BMC Genet 2013;14:30

53 Langmia IM, Apalasamy YD, Suki SZ, Omar SZ, Mohamed Z. Genetic association of AKAP10 gene polymorphism with reduced risk of preterm birth. J Perinatol 2015;35(9):700-704

54 Rocha FG, Slavin TP, Li D, Tiirikainen MI, Bryant-Greenwood GD. Genetic associations of relaxin: preterm birth and premature rupture of fetal membranes. Am J Obstet Gynecol 2013;209(3): 258.e1-258.e8

55 Vogel I, Hollegaard MV, Hougaard DM, Thorsen P, Grove J. Polymorphisms in the promoter region of relaxin-2 and preterm birth: involvement of relaxin in the etiology of preterm birth. In Vivo 2009;23(6):1005-1009

56 Uzun A, Laliberte A, Parker J, et al. dbPTB: a database for preterm birth. Database (Oxford) 2012;2012:bar069

57 Velez DR, Fortunato SJ, Thorsen P, Lombardi SJ, Williams SM, Menon R. Preterm birth in Caucasians is associated with coagulation and inflammation pathway gene variants. PLoS ONE 2008; 3(9):e3283

58 Velez DR, Fortunato S, Thorsen P, Lombardi SJ, Williams SM, Menon R. Spontaneous preterm birth in African Americans is associated with infection and inflammatory response gene variants. Am J Obstet Gynecol 2009;200(2):209.e1-209.e27

59 Zhang H, Baldwin DA, Bukowski RK, et al; Eunice Kennedy Shriver National Institute of Child Health and Human Development (NICHD) Genomic and Proteomic Network for Preterm Birth Research (GPN-PBR). A genome-wide association study of early spontaneous preterm delivery. Genet Epidemiol 2015;39(3): 217-226

60 Capece A, Vasieva O, Meher S, Alfirevic Z, Alfirevic A. Pathway analysis of genetic factors associated with spontaneous preterm birth and pre-labor preterm rupture of membranes. PLoS ONE 2014;9(9):e108578

61 Menon R, Conneely KN, Smith AK. DNA methylation: an epigenetic risk factor in preterm birth. Reprod Sci 2012;19(1):6-13 
62 Kacerovsky M, Lenco J, Musilova I, et al; PREBIC Biomarker Working Group 2012-2013. Proteomic biomarkers for spontaneous preterm birth: a systematic review of the literature. Reprod Sci 2014;21(3):283-295

63 Manuck TA. Pharmacogenomics of preterm birth prevention and treatment: a review. BJOG 2015

64 Uzun A, Sharma S, Padbury J. A bioinformatics approach to preterm birth. Am J Reprod Immunol 2012;67(4):273-277

65 Purcell S, Neale B, Todd-Brown K, et al. PLINK: a tool set for wholegenome association and population-based linkage analyses. Am J Hum Genet 2007;81(3):559-575

66 Kennedy B, Kronenberg Z, Hu H, et al. Using VAAST to identify disease-associated variants in next-generation sequencing data. Curr Protoc Hum Genet 2014;81:1, 25

$67 \mathrm{Hu} \mathrm{H}$, Huff CD, Moore B, Flygare S, Reese MG, Yandell M. VAAST 2.0: improved variant classification and disease-gene identification using a conservation-controlled amino acid substitution matrix. Genet Epidemiol 2013;37(6):622-634

68 Huang W, Sherman BT, Lempicki RA. Systematic and integrative analysis of large gene lists using DAVID bioinformatics resources. Nat Protoc 2009;4(1):44-57

69 Huang W, Sherman BT, Lempicki RA. Bioinformatics enrichment tools: paths toward the comprehensive functional analysis of large gene lists. Nucleic Acids Res 2009;37(1):1-13

70 Singleton MV, Guthery SL, Voelkerding KV, et al. Phevor combines multiple biomedical ontologies for accurate identification of disease-causing alleles in single individuals and small nuclear families. Am J Hum Genet 2014;94(4):599-610

71 Kim M, Cooper BA, Venkat R, et al. GEneSTATION 1.0: a synthetic resource of diverse evolutionary and functional genomic data for studying the evolution of pregnancy-associated tissues and phenotypes. Nucleic Acids Res 2015 